\title{
A EXPERIENCIA DE ACOMPANHAR UM FILHO HOSPITALIZADO: SENTIMENTOS, NECESSIDADES E EXPECTATIVAS MANIFESTADOS POR MÃES ACOMPANHANTES *
}

\author{
Edelia del Pilar Neira Huerta**
}

NEIRA HUERTA, E. del P. A experiência de acompanhar um filho hospitalizado: sentimentos, necessidades e expectativas manifestados por mães acompanhantes. Rev. Esc. Enf. USP, São Paulo, 19(2):153-171, 1985.

Este trabalho, realizado para atender uma motivação pessoal da autora, teve como finalidade $a$ de encontrar elementos que permitissem melhorar a assistência d mãe acompanhante em nosso meio. A população constou de mães que acompanhavam seus filhos internados em duas unidades pediátricas que apresentavam sistema de internação conjunta de caracteristicas diferentes, bem como diferenças quanto ao tipo de patologia assistida. Os dados foram colhidos por meio de entrevista, utilizando-se um formulário com perguntas abertas. Verificou-se que as mães acompanhantes sentem mais mal-estar do que bem-estar no hospital e que elas justificam seu mal-estar principalmente através de uma gama de razões relacionadas à situafão hospitalar; que a principal nececessidade das mães na situação estudada é dar cuidados ao filho, além de apresentarem necessidades como informaçöes; que as mães acompanhantes esperam contatos pessoais da equidpe hospitalar $e$ que o pessoal hospitalar dê assistência às crianças. Constatou-se também uma grande variedade de motivos determinando tanto as necessidades quanto as expectativas das mães, motivos esses que evidenciam a individualidade das mães $e$ dos significados únicos que a experiência de acompanhar um filho hospitalizado têm para cada uma delas.

\section{INTRODUÇÃO}

Nos anos em que trabalhei como enfermeira de unidades pediátricas sempre gostei muito de trabalhar com as mães de crianças hospitalizadas. Nos horários de visita, preocupava-me em orientá-las e ensiná-las para que, uma vez que a criança retornasse a seu lar, a mãe estivesse capacitada para atender adequadamente as necessidades de seu filho. Com essa finalidade, encorajava-as a participar dos cuiddos à criança e assim eu tinha oportunidade para supervisioná-las e corrigir suas técnicas e conhecimentos errados. Na época nunca duvidei da efetividade de minha assistência e sentia-me muito satisfeita com meu desempenho profissional.

- Dissertação de Mestrado apresentada à Escola de Enfermagem da USP, 1984. (Apresentaçăo condensada.)

* Enfermeira. Mestre em Enfermagem. Professor Assistente do Departamento de Enfermagem Materno-Infantil e Psiquiátrica da Escola de Enfermagem da USP - disciplina Enfermagem Podíbtrica. 
Ao iniciar minha experiência como docente, diferentes vivências me levaram a uma revisão de ações passadas e, entre essas ações, meu trabalho junto às mães de crianças hospitalizadas.

A disciplina da qual faço parte empregava - e continua a empregar - uma metodologia diferente, até então desconhecida para mim, que considera o aluno como um todo, constituindo de um sentir, um pensar e um querer, com potencial para detectar suas necessidades e que é capaz de refletir e agir construtivamente no atendimento das mesmas. Eu, como professora, devia desenvolver atitudes e habilidades que me permitissem criar um clima de respeito, confiança, compreensão e liberdade que ajudasse os alunos a identificar suas necessidades particulares de aprendizagem em enfermagem pediátrica, necessidades estas que constituiam a base do conteúdo programático da disciplina.

Concomitantemente, comecei a acompanhar o aprendizado prático dos alunos em unidades pediátricas que permitiam a presença contínua da mãe junto a seu filho hospitalizado. Era uma experiência desconhecida para mim, pois, até então somente conhecera a mãe visitante que permanecia por um tempo limitado na unidade.

Comecei a questionar a assistência que prestara às mães de crianças hospitalizadas: eu ensinava e orientava às mães, mas levava em conta suas necessidades particulares? Sabia identificar ou ajudar as mães a identificarem suas necessidades? Alguma vez conseguira realmente compreender seus sentimentos e suas expectativas no hospital? Compreendi que sempre me preocupara apenas com a saúde e o bem-estar da criança e só considerara a mãe como um recurso para o atendimento das necessidades dessa criança e não como uma pessoa que sente, pensa, tem vontades e age de maneira individual e única, muitas vezes independente de seu papel de mãe. Descobri, portanto, que tinha prestado assistência às mães atendendo aquelas necessidades que eu acreditara elas sentiam.

Nas unidades pediátricas que freqüentava com os alunos, pude observar, também, que a equipe de saúde mantinha-se distante, não interagindo com as mães; pareciam indiferentes a sua presença no hospital, e percebi que as mães me pareciam ansiosas e sem saber o que fazer ou como se comportar no hospital.

Quis então aprender a prestar assitência às mães acompanhantes; procurei bibliografia e comecei a estudar. Na bibliografia consultada pude verificar que a presença da mãe junto ao filho hospitalizado tem sido vista por diferentes autores como benéfica, tanto para a criança como para a própria mãe (BOLWBY ${ }^{3}$, ROBERTSON ${ }^{24}$, PRUGH et alii ${ }^{22}$, NOLAN ${ }^{21}$, HARDGROVE \& RUTLEDGE ${ }^{11}$, ROY ${ }^{25}$, FAGIN ${ }^{7-8}$, BRIGHT ${ }^{4-5}$, MAHAFFY ${ }^{17-18-19}$, MAC CARTHY ${ }^{16}$, WOFFINDIM ${ }^{33}$, VERMILLION et alii ${ }^{31}$ e HOHLE ${ }^{14}$ ). Alguns autores apontavam, também, as múltiplas vantagens que a permanência contínua da mãe junto ao filho doente no hospital tem para a equipe hospitalar (VAN DER SHYFF ${ }^{30}$, MARLOW ${ }^{20}$, NOLAN ${ }^{21}$, MAC CARTHY ${ }^{16}$ e VERMILLION et alii ${ }^{31}$ ). Pude constatar que, na maioria dos trabalhos, os autores nos mostram sua percepção do que a experiência de acompanhar um filho hospitalizado significa para os pais (HARRIS ${ }^{12}$, COFFIN 6, MARLOW ${ }^{20}$, 
SCHRAEDER ${ }^{26}$, SCOFIELD ${ }^{27}$, FLETCHER ${ }^{9}$, WHALEY \& WONG ${ }^{32}$, SMITH et alii ${ }^{28}$, BARBOSA ${ }^{1}$, BRIGHT ${ }^{4-5}$, HARTRICH ${ }^{13}$, KOSS \& TETER ${ }^{15}$, RAMOS \& MORAES ${ }^{23}$ e SMITHERMAN ${ }^{29}$ ). Nesses trabalhos percebi que a preocupação primordial é o atendimento das necessidades da criança.

$\mathrm{Na}$ bibliografia estudada pude verificar, também, que são escassos os trabalhos, todos eles de autores estrangeiros, em que se constata a preocupação em analisar a experiência de acompanhar um filho hospitalizado do ponto de vista dos pais (FREIBERG ${ }^{10}$, NOLAN ${ }^{21}$ e BAXTER ${ }^{2}$ ).

Para atender minha motivação e, com a finalidade de encontrar elementos que permitam melhorar a assistência à mãe acompanhante em nosso meio, resolvi então procurar respostas para os seguintes questionamentos: o que as mães em situação de acompanhante hospitalar de um filho doente sentem, precisam e esperam da equipe hospitalar? Como elas explicam esses sentimentos, necessidades e expectativas? Existem fatores na situação hospitalar que influenciem nos significados atribuídos por elas à experiência?

Para responder esses questionamentos foi elaborado este estudo exploratório, com o objetivo de conhecer, em unidades pediátricas de características diferentes, os sentimentos, as necessidades e as expectativas das mães acompanhantes em relação à equipe hospitalar, bem como as razões para os mesmos.

\section{METODOLOGIA}

\section{População e local}

Para atingir o objetivo do trabalho foram entrevistadas 40 mães vivenciando o segundo dia da experiência de acompanhar seus filhos hospitalizados em duas unidades pediátricas de características diferentes, de um hospital de ensino de caráter governamental da cidade de São Paulo, 20 mães em cada unidade.

No quadro a seguir pode-se observar as características das unidades que foram consideradas na realização deste estudo.

\section{CARACTERISTICAS DAS UNIDADES ONDE O ESTUDO FOI REALIZADO}

\section{UNIDADE I}

- a mãe permanece obrigatoriamente junto ao filho;

- presta assistência as crianças portadoras de doenças agudas, ou em fase aguda de diferentes patologias;

- as acomodações oferecidas às mães são precárias, (Anexo 1).

\section{UNIDADE II}

- é oferecida à mãe a alternativa de acompanhar, ou não, seu filho durante a hospitalização;

- assiste crianças portadoras de doenças crônicas, neoplásicas e, principalmente, de etiologia não definida ou por esclarecer;

- as mães dispõem de acomodações melhores, (Anexo 1).

As vinte (20) mães que se encontravam na Unidade I constituiram o Grupo I, e as 20 mães que estavam na Unidade II formaram o Grupo II. 


\section{Coleta dos dados}

Os dados foram colhidos por meio de entrevista, utilizando-se um formulário constituído de 3 partes (Anexo 2): a primeira referia-se a dados de identificação da criança; a segunda, a dados de identificação da mãe e dados sócio-econômicos da família, e a terceira, continha perguntas abertas abrangendo aspectos relativos aos sentimentos e necessidades das mães acompanhantes, bem como as suas expectativas em relação à equipe hospitalar.

Em relação ao procedimento de coleta de dados, após verificar se a situação da mãe correspondia ao critério estabelecido para a seleção da amostra, ou seja, mãe vivenciando o segundo dia de experiência de acompanhar seu filho hospitalizado, comunicava-se ao pessoal da unidade que essa mãe seria entrevistada, isto com a intenção de diminuir as interferências ambientais e de possibilitar um mínimo de privacidade para a entrevista. Cada mãe foi entrevistada junto a seu filho, de modo a não se alterar a situação de acompanhante hospitalar.

Com o objetivo de estabelecer um clima de confiança que promovesse respostas o mais espontâneas possíveis, apresentava-me à mãe, expunha-lhe a finalidade do estudo, ressaltando o aspecto sigiloso do mesmo. Deixava também claro que eu não tinha vínculo empregatício com o hospital e, principalmente, que ela tinha toda a liberdade de participar, ou não, do estudo. Nenhuma das mães selecionadas se recusou a participar.

Todos os dados e informações incluídos no instrumento de coleta foram solicitados às mães, exceto o diagnóstico da criança que se obtinha do prontuário hospitalar após o término da entrevista. Esta medida foi tomada para evitar a influência desse diagnóstico no meu comportamento durante a entrevista.

No registro das respostas das mães utilizou-se, na medida do possivel, a mesma linguagem empregada pelas mães.

Um fato que muito me alegrou, foi que a maioria das mães entrevistadas me agradeceram no final da entrevista, inclusive antes de eu conseguir expressar-lhes meu agradecimento por ter colaborado com meu estudo. A partir desse fato, comecei a sentir e compreender que estava aprendendo a prestar assistência, fundamentada em uma compreensão empática, às mães acompanhantes.

Durante a coleta de dados percebi que algumas mães tinham experiência anterior como mãe acompanhante e outras estavam vivenciando sua primeira experiência. Com o objetivo de homogeneizar a amostra quanto a experiência anterior, ou não, cada Grupo foi dividido em dois (2) subgrupos de dez (10) mães cada um; a saber:

- subgrupos $A$ : mães vivenciando a primeira experiência como mãe acompanhante; e

- subgrupos B: mães com experiência anterior de acompanhar um filho doente em algum hospital. 


\section{Tratamento dos dados}

A partir do agrupamento das idéias semelhantes contidas nas respostas das mães, identificou-se categorias para essas informações. Todos os dados foram analisados basicamente em relação aos percentuais obtidos.

\section{RESULTADOS E COMENTARIOS}

As mães que fizeram parte do estudo, em sua maioria eram casadas $(82,5 \%)$ e tinham entre 26 e 35 anos de idade $(57,5 \%)$. As mães do Grupo II apresentaram, em conjunto, nivel de escolaridade mais elevado, bem como melhor nivel sócio-econômico do que as mães do Grupo I e, estas últimas tinham, em geral, maior número de filhos.

$\mathrm{O}$ agrupamento das respostas das mães acompanhantes a respeito de como se sentem no hospital pode ser observado na tabela 1 .

Pelos dados da Tabela 1 podemos observar que as mães de ambos os Grupos sentem mais mal-estar do que bem-estar no hospital e que as mães expressaram seu sentir no hospital de diferentes maneiras, constatando-se diferenças entre os dois Grupos quanto à forma de expressão. As mães do Grupo II verbalizaram seu mal-estar no hospital principalmente através de uma gama de sentimentos relacionados a sofrimento como preocupada, triste, nervosa. As mães do Grupo I, além de apresentarem sentimentos relacionados a sofrimento, verbalizaram maior número de sensaçōes corporais desagradáveis (cansada, com sono) para expressarem seu mal-estar no hospital.

Através dos dados obtidos, podemos verificar a influência das características próprias de cada local nessas expressões. As mães que expressaram maior número de sentimentos relacionados a sofrimento, Grupo II, acompanhavam crianças portadoras de doenças crônicas, neoplásicas e, principalmente, portadoras de patologias de etiologia por esclarecer. Por outro lado, o maior número de expressões relacionadas a mal-estar, através de sensações corporais desagradáveis, corresponderam às mães que se encontravam na Unidade I, que, como apresentado no quadro "Características das Unidades" onde o estudo foi realizado, oferece acomodações precárias às mães.

Vale a pena ressaltar que as mães também verbalizaram espontaneamente, principalmente mal-estar, em outros momentos da entrevista, ficando desse modo evidente a importância e a necessidade de se prestar atenção a todas as verbalizações dos pais no hospital, se quisermos ser efetivos na nossa assistência, isto é, a importância e a necessidade de saber ouvir.

As mães acompanhantes explicaram seu mal-estar no hospital, principalmente através de idéias relacionadas à situação hospitalar $(80,6 \%)$, como pode ser observado na Tabela 2 , bem como, em menor porcentagem, por meio de idéias não relacionadas à situação hospitalar $(19,4 \%)$.

$\mathrm{Na}$ categoria relacionadas à situação hospitalar podemos observar uma grande variedade de motivos, 13 razões, junto com uma elevada porcentagem de idéias, $13,8 \%$, que, apesar de se relacionarem à situação hospitalar, não guardaram relação com nenhum dos outros motivos. 


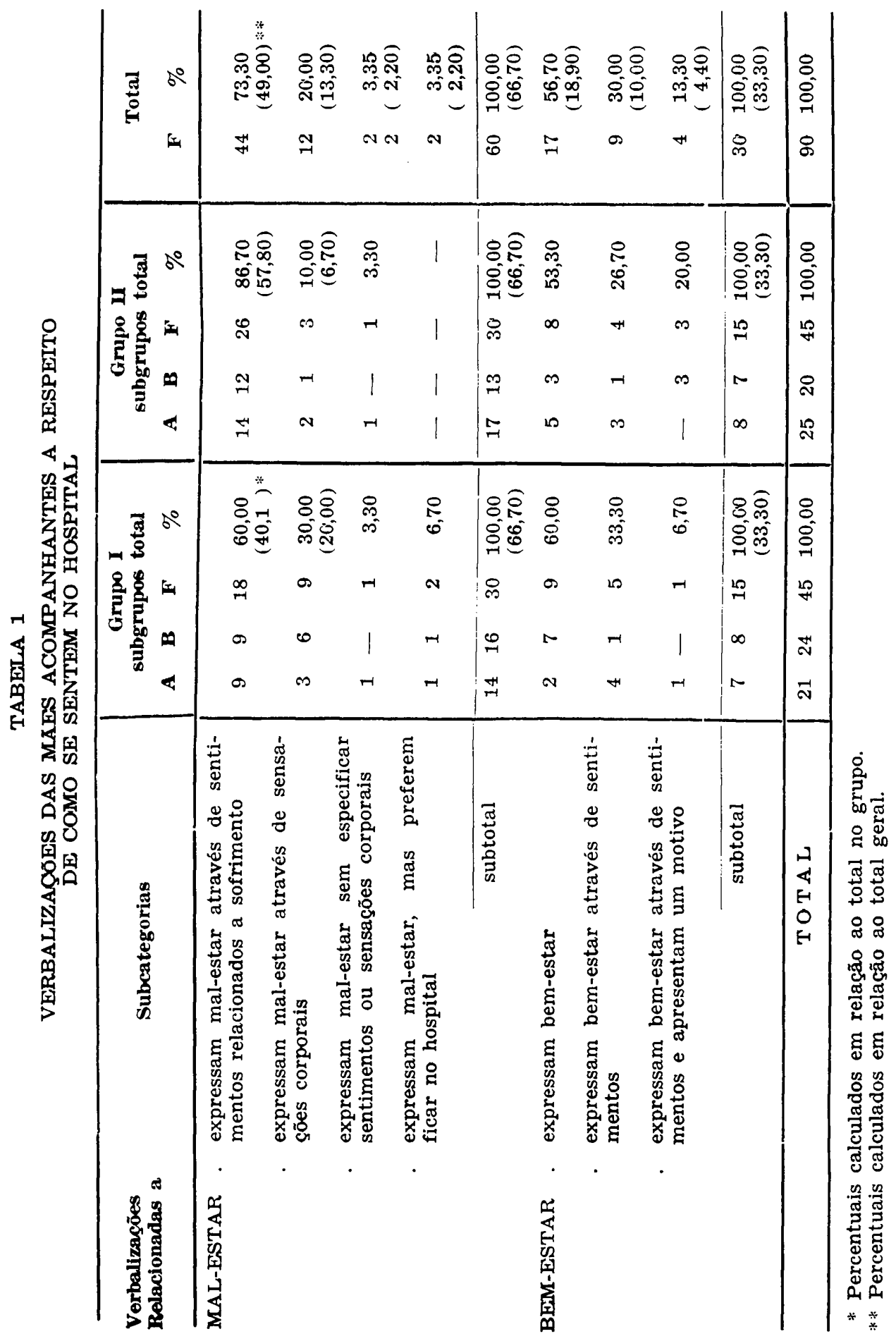


Essa grande variedade põe em evidência a individualidade de significados emocionais que as mães atribuem à experiência de mãe acompanhante, ou seja, cada mãe reage de um modo particular à experiência de acompanhante hospitalar de seu filho doente.

Podemos observar, na Tabela 2, diferenças entre o Grupo I e o Grupo II quanto à distribuição nas diferentes subcategorias de justificativas que se relacionam à situação hospitalar, e constatar a influência das características próprias de cada local nesses resultados. Assim, os motivos incerteza quanto à recuperação do filho e revolta pela doença do filho foram apresentados somente pelas mães do Grupo II, que também apresentaram cinco (5) das seis (6) justificativas relacionadas com medo - medo do que poderia acontecer; medo de pensar / imaginar coisas. Verifica-se desse modo a influência do diagnóstico da criança, uma das características da Unidade II, nessas justificativas.

Por outro lado, somente as mães do Grupo I apresentaram justificativas relacionadas com acomodações deficientes e podemos ver, pelos dados da Tabela 2, que essa justificativa, em conjunto com necessidades fisiológicas insatisfeitas, correspondem a um terço das justificativas referidas pelas mães do Grupo I para explicar seu mal-estar no hospital. Este resultado demonstra a influência da precariedade das acomodações oferecidas pela Unidade I sobre as respostas das mães desse Grupo. Fica também uma dúvida: até que ponto a obrigatoriedade de permanecer junto ao filho, outra das caracteristicas da Unidade I, influenciou nesses resultados?

Os resultados da tabela 2 demonstram, também, diferenças de percepção entre as mães dos dois Grupos. As mães do Grupo II parecem perceber mais os outros - o filho, as outras pessoas do ambiente crianças, outras mães - até mesmo o próprio ambiente, do que as mães do Grupo I, que parecem mais voltadas para si próprias, seu conforto e suas necessidades fisiológicas.

Em geral as justificativas para o mal-estar no hospital que se relacionam à situação hospitalar nos mostram os fatores da situação hospitalar que provocam mal-estar nas mães, muitos dos quais, como falta de informações e acomodações deficientes, podem e devem ser evitados.

As justificativas agrupadas na categoria não relacionadas à situação hospitalar foram mais apresentadas pelas mães do Grupo I que, como referido anteriormente, tinham, em geral, maior número de filhos e que, não tinham oportunidade de providenciar cuidados para os outros fithos ou alguém que 'olhasse' sua casa, desde que eram obrigadas a permanecer junto ao filho no hospital.

$\mathrm{Na}$ Tabela 2 podemos observar ainda, a influência do número de experiências como mãe acompanhante nos resultados; as mães com experiência anterior apresentaram maior número de justificativas relacionadas com acomodações deficientes, como também maior número de justificativas não relacionadas à situação hospitalar.

Quanto aos motivos oferecidos pelas mães acompanhantes para justificar seu bem-estar no hospital, a tabela 3 indica o resultado de seu agrupamento. 


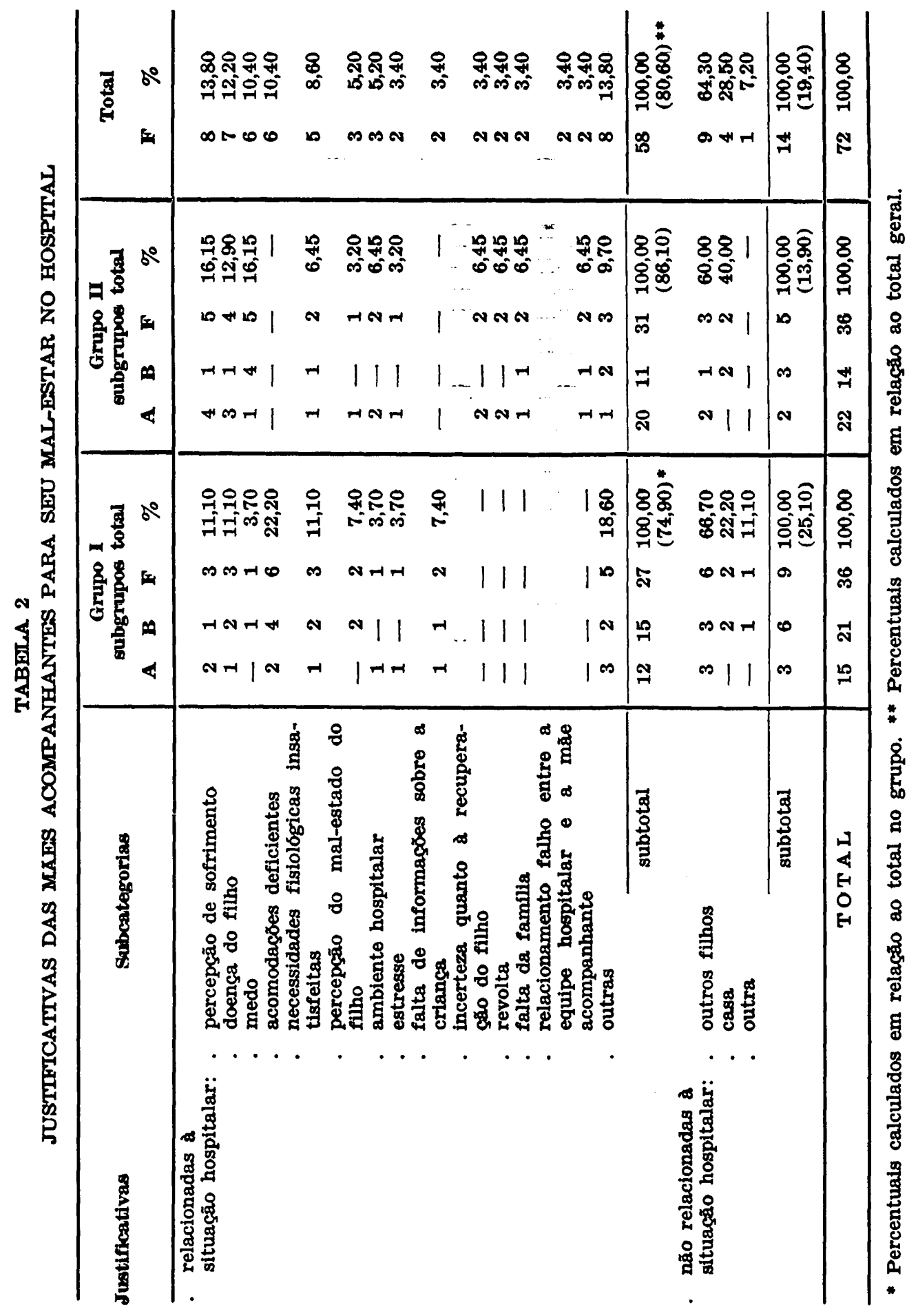




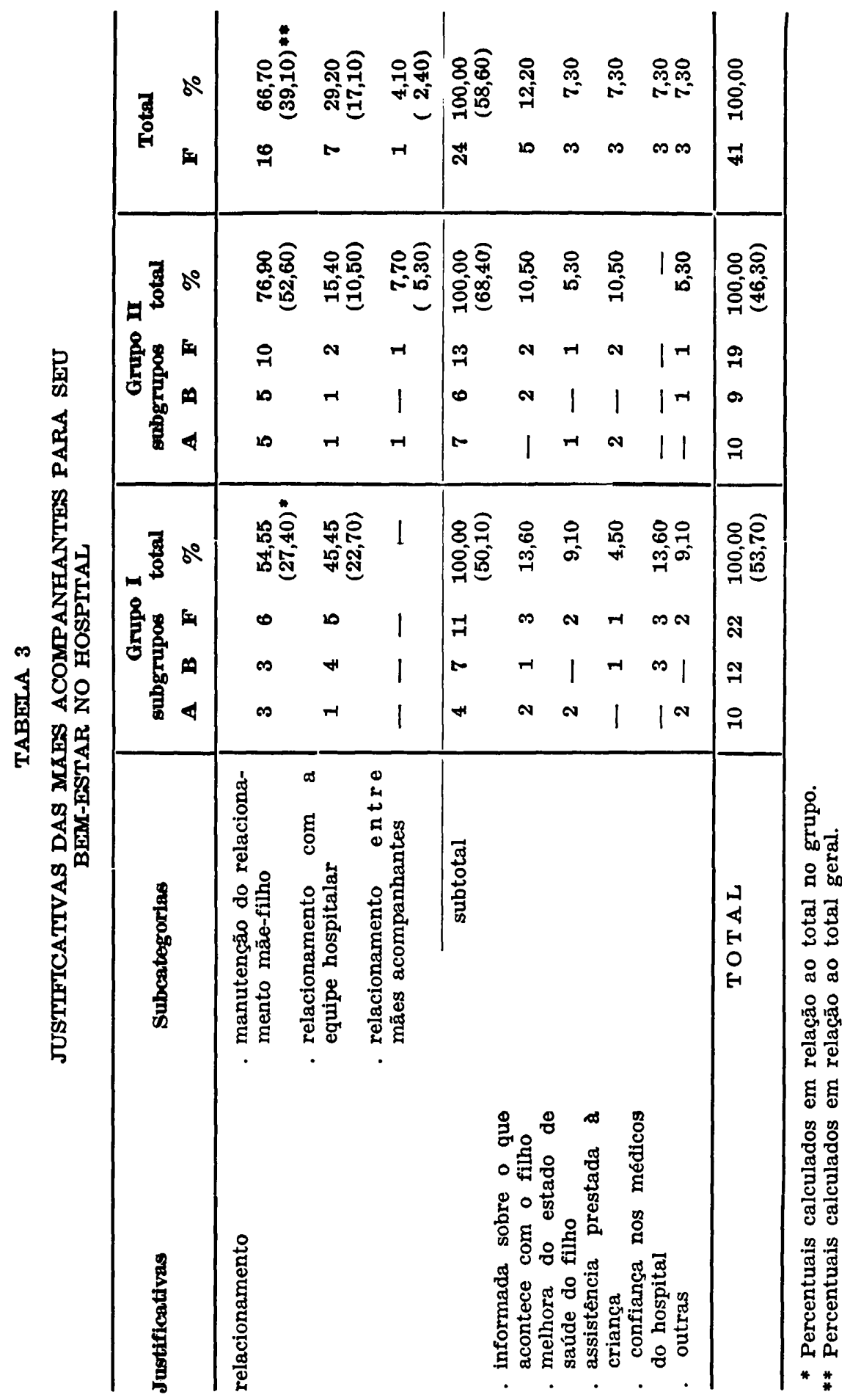


Pelos dados da tabela 3 podemos constatar a importância do fator relacionamento para o bem-estar das mães no hospital. A maioria das justificativas a esse respeito $(66,7 \%)$ relaciona-se à manutenção do relacionamento mãe-filho, ou seja, as mães se sentem bem no hospital principalmente por estarem junto ao filho e poderem atender necessidades recíprocas com eles. Observamos que esse motivo foi mais apresentado pelas mães do Grupo II do que pelas mães do Grupo I, provavelmente devido às diferenças de percepção antes mencionadas.

Os motivos ou razões oferecidos pelas mães deste estudo para explicar seu bem-estar no hospital apontam o que pode e deve ser feito para que elas se sintam bem no hospital; assim, é necessário mantê-las informadas, prestar assistência adequada a seus filhos e, principalmente, relacionar-se com elas.

Em relação às necessidades das mães acompanhantes, na Tabela 4 podemos observar que as mães do estudo apresentaram principalmente necessidades relativas ao cuidado do filho e a informações, junto com necessidades relativas a maior conforto físico e à recuperação da saúde do filho.

Nessas necessidades é evidente a influência das características próprias de cada local, pois as mães do Grupo II apresentaram maior número de necessidades relativas ao cuidado do filho e a informações relacionadas com a doença do filho; em ambas, portanto, fica evidente a influência do diagnóstico da criança. As mães do Grupo I, por sua vez, apresentaram maior número de necessidades relacionadas com maior conforto físico, o que demonstra a influência das acomodações nessas respostas. Por outro lado, acredito que a obrigatoriedade de permanecer junto ao filho também exerceu certa influência nessas respostas.

Pelos dados da Tabela 4 é possivel perceber a influência do número de experiências como mãe acompanhante nas necessidades referidas pelas mães; as mães vivenciando a primeira experiência, subgrupos A, apresentaram maior número de necessidades relativas ao cuidado do fitho do que as mães dos subgrupos $\mathrm{B}$, e somente mães dos subgrupos $\mathrm{A}$ apresentaram necessidades de orientação e/ou ajuda para dar cuidados ao filho.

A primeira categoria de necessidades, isto é, necessidades relativas ao cuidado do filho, demonstra que a principal necessidade das mães no hospital é continuar sendo mães. As diferentes idéias incluídas nessa categoria mostram que as mães têm diferente força ou recursos internos para continuar sendo mães no hospital e, conseqüentemente, o atendimento de suas necessidades relacionadas com dar cuidados ao filho também será diferente. Assim, algumas mães, precisam apenas de encorajamento para cuidar do filho, outras, de orientação e/ou ajuda para fazê-lo, e ainda outras mães necessitam que outros deêm cuidados a seu filho.

Quanto às expectativas das mães acompanhantes em relação à equipe hospitalar, podemos observar na Tabela 5 que as mães apresen- 


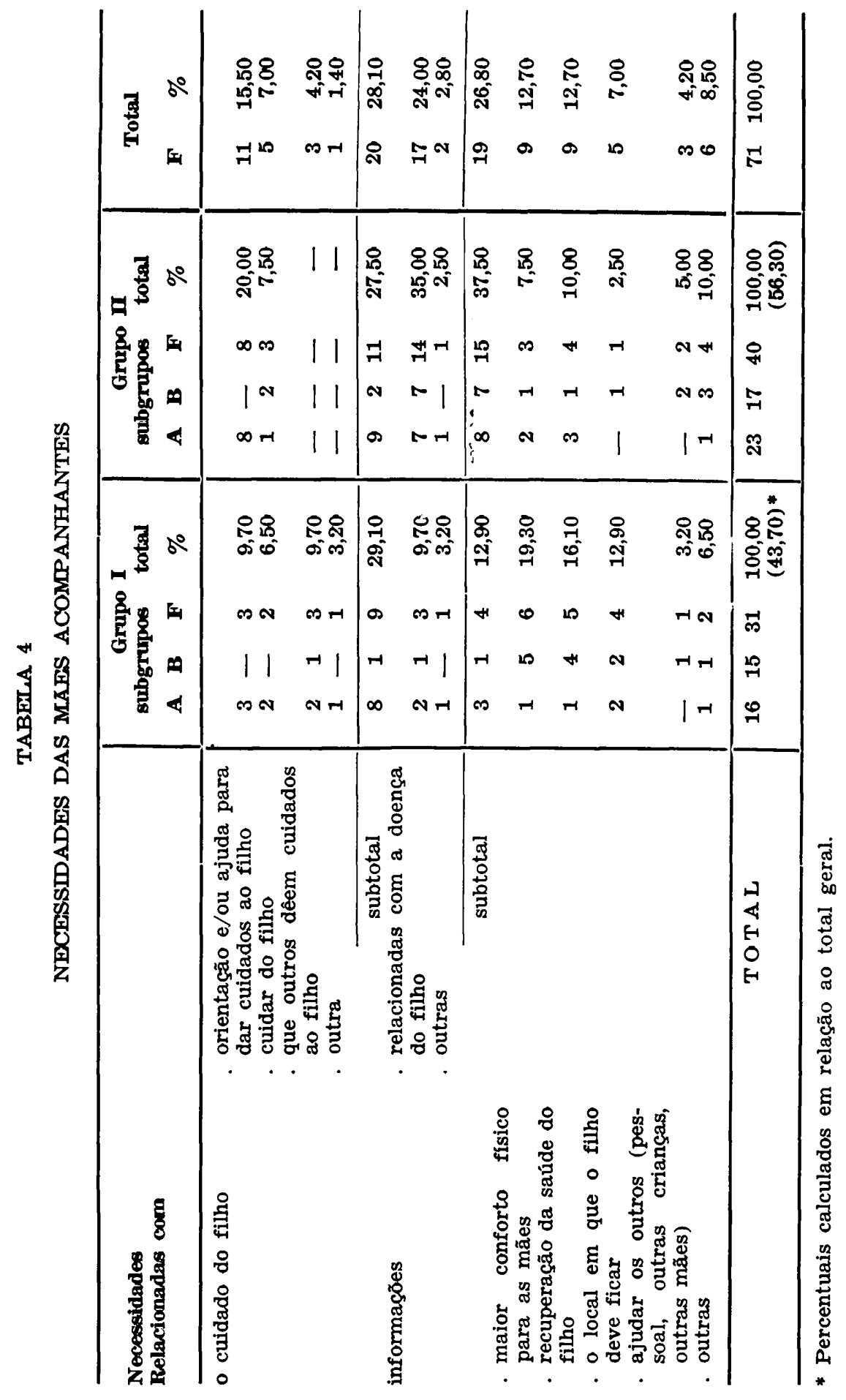




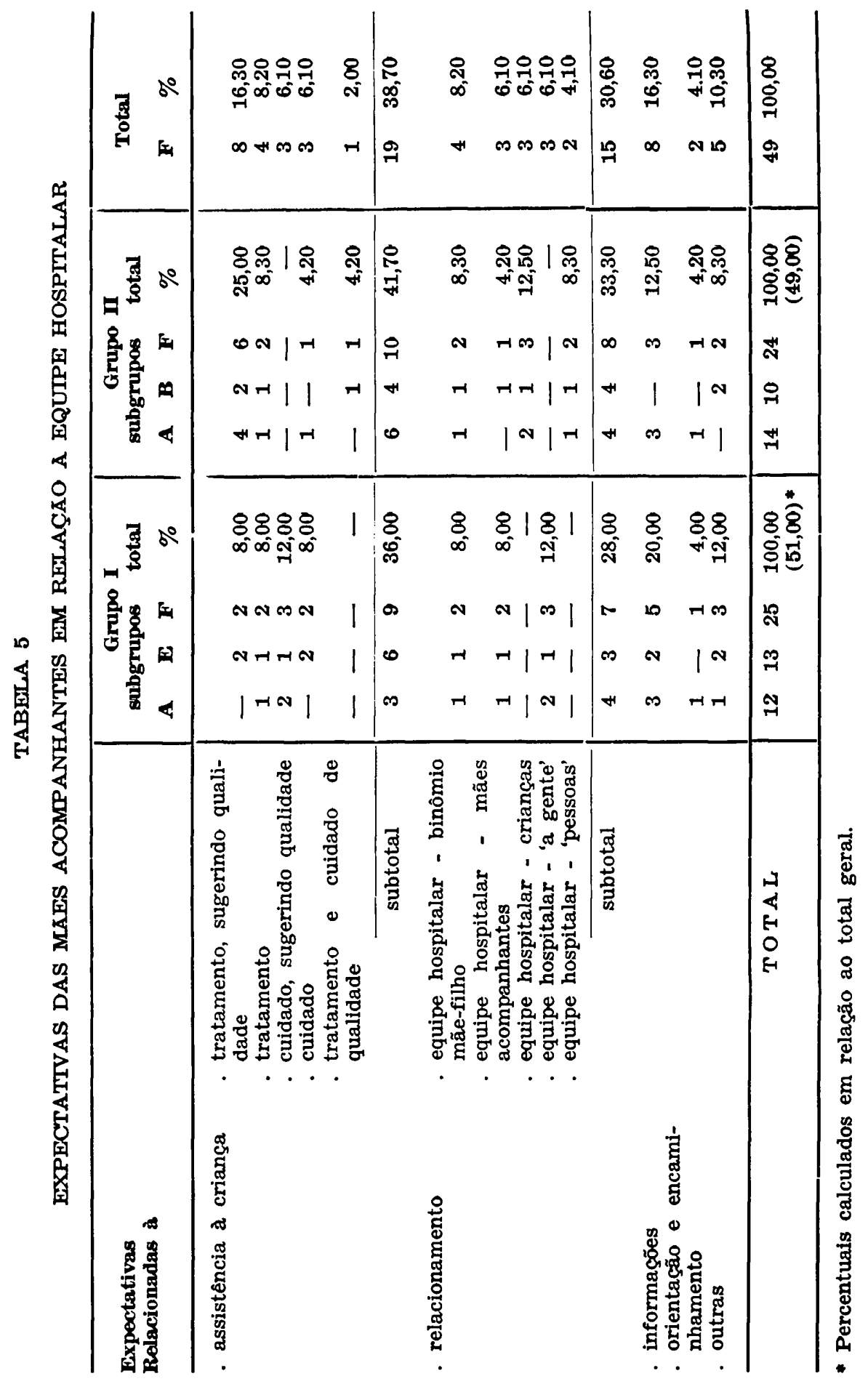


taram expectativas relacionadas com: assistência à criança, relacionamento, informações e orientação e encaminhamento.

Pelos resultados desta tabela podemos também verificar a influência das características próprias de cada Unidade nas expectativas das mães. As mães do Grupo II, unidade em que as crianças apresentam doenças de características incomuns, que requerem uma assistência mais complexa, com maior número de exames e procedimentos, apresentaram suas expectativas a esse respeito principalmente através da idéia tratamento, sugerindo muitas vezes qualidade para esse tratamento. As mães do Grupo I que acompanhavam, em sua maioria, crianças portadoras de doenças comuns na infância, verbalizaram suas expectativas relacionadas com assistência à criança tanto através da idéia cuidado como da idéia tratamento.

$\mathrm{Na}$ mesma tabela podemos constatar também a influência do número de experiências como mãe acompanhante nas expectativas das mães; as mães dos subgrupos $\mathrm{A}$, vivenciando sua primeira experiência, apresentaram maior número de expectativas relacionadas com informações, e somente mães desses subgrupos apresentaram expectativas relacionadas com orientação e encaminhamento.

Desde que relacionamento, informações e orientação e encaminhamento implicam em aproximação, comunicação e interações evidenciamos que, do total de expectativas em relação à equipe hospitalar apresentadas pelas mães acompanhantes (49), o maior número, 25, distribuídas de maneira similar em ambos os Grupos, dizem respeito a contatos pessoais entre a equipe hospitalar e seus clientes.

$E$ importante ressaltar que as mães pertencentes à amostra deste estudo se referiram principalmente ao médico como o integrante da equipe hospitalar que poderia ajudá-las no atendimento, tanto de suas necessidades quanto de suas expectativas. Houve escassas referências aos outros membros da equipe, entre os quais a enfermeira e outros membros da equipe de enfermagem estão incluídas.

Cabe também destacar que 12 mães da amostra não sabiam quem poderia ajudá-las no atendimento de suas necessidades no hospital, como também me parece importante o fato de que a maioria das mães esperava que todos os integrantes da equipe hospitalar - do porteiro à diretoria do hospital - se relacionasse com elas e com as crianças.

Quanto às justificativas oferecidas pelas mães acompanhantes, tanto para suas necessidades quanto para suas expectativas em relação à equipe hospitalar, encontramos nelas um fenômeno que se apresentou como uma característica das justificativas das mães e que foi uma enorme variedade de idéias ou motivos. Essa variedade de motivos evidenciou a individualidade das mães acompanhantes e a necessidade de se conhecer e compreender esses motivos individuais se quisermos prestar-lhes assistência efetiva.

Um fato curioso foi que 7 mães da amostra ofereceram $o$ motivo obrigação ou dever da equipe hospitalar para justificar suas expectativas 
em relação à equipe. Chama a atenção que essas mães não exijam o cumprimento daquilo que elas consideram uma obrigação do pessoal hospitalar.

Os motivos ou idéias determinando tanto o sentir quanto o querer das mães acompanhantes mostrou a individualidade dos significados que a experiência de acompanhar um filho hospitalizado teve para cada uma das mães que fizeram parte deste estudo.

\section{CONCLUSÕES}

De acordo com os resultados deste estudo foi possível chegar às seguintes conclusões: no hospital;

- as mães acompanhantes justificam seu mal-estar no hospital principalmente através de uma variedade de idéias relacionadas à situação hospitalar;

- o principal fator que contribui para o bem-estar das mães acompanhantes é relacionamento, sendo que a maior porcentagem de verbalizações a esse respeito se referem à manutenção do relacionamento mãe-filho;

- a principal necessidade das mães no hospital é cuidar do filho e as verbalizações a esse respeito permitem compreender que as mães são diferentes, apresentando força ou recursos internos diferentes para continuar sendo mães no hospital;

- as necessidades de informações, de maior conforto físico e de recuperação da saúde do filho também se apresentaram como sendo importantes para as mães do estudo;

- as mães esperam principalmente contatos pessoais da equipe hospitalar, como também que o pessoal do hospital dê assistência a seus filhos;

- a existência de uma grande variedade de motivos, determinando tanto as necessidades quanto as expectativas das mães acompanhantes, demonstra a individualidade das mães e permite concluir a importância de se considerar cada mãe como uma pessoa diferente e única;

- as características próprias das unidades onde o estudo foi realizado exerceram influência nos significados que a experiência de acompanhar o filho hospitalizado têm para as mães.

Os resultados obtidos permitiram ainda concluir que:

- o número de experiências como mães acompanhante, a escolaridade, o estrato sócio-econômico e o número de fithos exerceram influência nas respostas das mães; e 
- assistência e cuidado ao filho junto com relacionamento são os fatores de maior importância nos significados que a experiência de acompanhar um filho hospitalizado têm para as mães.

NEIRA HUERTA, E. del P. Rooming-in experience: feelings, needs and expectations referred by living-in mothers. Rev. Esc. Enf. USP, São Paulo, 19(2):153-171, 1985.

This work had the finality of searching elements to improve the living-in mothers assistance in our hospitals. The population under study included accompanying mothers in two different pediatric units. The differences between the two units were with respect to room accomodations for mothers and stipulations as to the type of disease pathology being treated. The data was collected by way of interviews in which a questionnaire of open questions was used. Results showed that the rooming-in mothers of the sample felt more discomfort than confort in the hospital, due to many different aspects of the hospital situation; the principal need of the studied mothers was to be able to give care to their children, while others needs related to receiving information about their child's condition. The living-in mothers expected to have personal contact with the hospital health team while the hospital personnel would be giving assistance to the children. Many reasons were given for the varying needs and expectations of the rooming-in mothers, showing the individuality of these women and the different ways in which a living-in experience affect different mothers.

\section{REFERENCIAS BIBLIOGRAFICAS}

1. BARbOSA, L.T. Aspectos psico-sociais da assistência à criança. São Paulo, Nestlé, Serviço de Informação Clentifica, s.d. (Temas de Pediatria, 9).

2. BAXTER, P. Frustration felt a mother and her child during the child's hospitalization. Mater. Child Nurs. J., Pltsburg, 1(3):159-61, May/June 1976.

3. BOWLBY, J. Cuidados maternos e aaude mental. São Paulo, Martins Fontes, 1981.225 p.

4. BRIGHT, F. Parental anxiety - a barrier to communication. In: AMERICAN NURSE'S AssOCIATION. Ana Clinical Sessions: 1966. New York, Appleton-Century-Crofts, 1966. p.13-20.

5. The pediatric nurse and parental anxiety. Nurs. Forum, Hillsdale, 4(2):30-47, May 1965.

6. COFFIN, M.A. Visiting hours for parents. Amer. J. Nurs., New York, 55(3):329, Mar. 1955.

7. FAGIN, C.M. Pediatric rooming-in: its meaning for the nurse. Nurs. Clin. North Amer., Philadelphia, 1(1):83-93, Mar. 1966.

8. Why not involve parents when children are hospitalized? Amer. J. Nurs., New York, 62(6):78-9, June 1962.

9. FletCher, B. Rooming-In: a reassessment. Mater. Child Nurs. J., Pittsburg, 10(2):85-98, Summer 1981.

10. FREIBERG, K. How parents react when their child is hospitalized. Amer. J. Nurs., New York, 72(7):1270-2, July 1972.

11. HARDGROVE, C. \& RUTLEDGE, A. Parenting during hospitalization. Amer. J. Nurs., New York, 75(5):836-8, May 1975 .

12. HARRIS, P.J. How parents feel. Nurs. Times, London, 77(42):1803-4, Oct. 1981.

13. HARTrICH, P. Parents and nurses work together. Nurs. Outlook, New York, 4(3):146-8, Mar. 1956. 
14. HOHLE, B. We admit parents too. Amer. J. Nurs., 57(7):865-7, July 1957.

15. KOSS, T. \& TETER, M. Welcoming a family when a child is hospitalized. MCN, New $v$ York, 5(1):51-4, Jan/Feb. 1980.

16. MAC CARTHY, D. The under fives in hospital. Nurs. Times, London, 77(30; suppl): 22-8, July 1981 .

17. MAHAFF', P. Admissions interviews with parents. Amer. J. Nurs., New York, 66(3): 506-8, Mar. 1966.

18. — Nurse-parent relationships in living-in situations. Nurs. Forum, Hillsdale, 3(2): 53-68, May 1964.

19. The effects of hospitalization on children admitted for tonsillectomy and adenoidectomy. Nurs. Res., New York, 14(1):12-9, Mar. 1965.

20. MARLOW, D. Texbook of pediatric nursing. 5. ed., Phlladelphia, Saunders, 1977.949 p.

21. NOLAN, H. Hospitalization of infants and pre-schoolers - observations and reflections of by a live-in mother. Lamp, Sidney, 38(8):29-35, Aug. 1981.

22. PRUGH, D. et alil. A study of the emotional reactions of children and families to hospitalization and illness. Amer. J. Orthopsychiatry, New York, 23(1):70-106, Jan. 1953.

23. RAMOS, T.A.G. \& MORAES, E. Papel da enfermeira junto a mães de crianças hospitalizadas. Rov. Bras. Enf., Brasilia, 29(2):45-55, abr./jun. 1976.

24. ROBERTSON, J. Some responses of young children to the loss of maternal care. Nurs. Times, London, 49(16):382-6, Apr. 1953.

25. ROY, C. Role cues for the mother of the hospitalized child. In: AMERICAN NURSE'S ASSOCIATION. Ana clinical Sessions: 1968. New York, Appleton-Century-Crofts, 1968. p.199-206.

26. SCHRAEDER, B. Attachment and parenting despite lengthy intensive care. MCN, Neww York, 5(1):37-41, Jan./Feb. 1980.

27. SCOFIELD, C. Parents in the hospital. Nurs. Clin. North. Amer., Philadelphia, 4(1):59-67, Mar. 1969.

28. SMITH, M. et alli. Child and family: concepts of nursing practice. New York, Mac Graw Hill, 1982. 1246 p.

29. SMITHERMaN, C. Parents of hospitalized children have needs, too. Amer. J. Nurs., New York, 79(8):1423-4, Aug. 1979.

30. VAN DER SHYFF, G. The role of parents during their child hospitalization. Austral. Nurs. J., Port Adelaide, 8(11):57-61, June 1979.

31. VERMILLION, B. et alil. The effective use of parent care unit for infants on the surgical service. J. Pediat. Surg., New York, 14(3) :321-4, June 1979.

32. WHALEY, L.F. \& WONG, D.L. Essentials of pediatric nursing. Saint Louis, Mosby, 1982. 943 p.

33. WOFFINDIM, K.E. Children and their parents in hospital. Nurs. Times, London, 77 (suppl. 8) 31-2, Mar. 1981. 


\section{ANEXO 1}

\section{ACOMODACOES OFERECIDAS AS MAES ACOMPANHANTES NAS UNIDADES I E II}

\section{Unidade I}

- cadeiras comuns de fórmica localizadas ao lado de cada berço ou maca, sendo que o espaço físico disponível para a unidade da criança e da mãe, dentro das enfermarias, é de $3 \mathrm{~m}^{2}$ em média;

- um banheiro, não privativo para as mães, provido de pia, vaso sanitário e chuveiro, situado a 12,5 metros da unidade;

- telefone público na portaria do hospital;

- diariamente săo oferecidas 4 refeições às mães:

- café da manhã, composto de café ou chá com leite e pão com manteiga;

- almoço e jantar, em que é oferecido sopa e pão; e

- um lanche às 21 horas, canstituído de café ou chá com leite e pão com manteiga.

Dependendo do número de mães acompanhantes, é oferecida às mães a possibilidade de repetir qualquer uma dessas refeiços;

\section{Unidade II}

- poltronas estofadas e reclináveis, com suas respectivas banquetas para apoio dos pés, localizadas ao lado de cada berço ou cama. O espaço disponível para a unidade da criança e da mãe, dentro das enfermarias, 6 de 4,5 m² em média;

- uma salinha, de $9 \mathrm{~m}^{2}$, mobiliada com uma mesa, 4 cadeiras de fórmica e 2 poltronas, destinada a servir de refeitório e sala de descanso para as mães; nesta sala elas podem fumar se assim o desejarem;

- um banheiro, de uso exclusivo, provido de pia, vaso sanitário e chuveiro, situado junto à sala acima mencionada;

- telefone público na portaria do hospital;

- diariamente são oferecidas 4 refeiçoes às mães:

- café da manhã, composto de café ou chá com leite e păo com manteiga;

- almoço e jantar, em que é oferecido sopa e păo; $\theta$

- um lanche às 21 horas, constituido de café ou chá com leite e pão com manteiga.

Dependendo do número de mães acompanhantes, é oferecida às mães a possibilidade de repetir qualquer uma dessas refeiçžes.

- as mães, com melhores recursos econômicos, têm ainda a possibilidade de tomar algum lanche ou refeição diferente nos numerosos locais do gênero que existem nas imediaçes do hospital. 


\section{ANEXO 2}

FOLHA DE REGISTRO DE ENTREVISTA A MAE ACOMPANHANTE

No de formulário:

Data:

Tempo:

Unidade:

I. IDENTTIFTCAÇAO DA CRIANÇA:

Nome:

Diagnóstico:

No de internações:
Data de nasc.:

Idade:

Posição entre os irmãos:

II. IDENTIFICAÇĀO DA MAE:

Nome:

Idade: Estado civil S-C-V-D-MJ

$\mathrm{N}^{\circ}$ de filhos: ... $\mathrm{N}^{\circ}$ de experiências como mãe acompanhante:

DADOS SOCIO-ECONOMICOS DA FAMILIA:

Habitação: Bairro em que mora: (centro-periferia-rural)

Tipo: T - S - Apto. - B - outras

Posse: própria - alugada - cedida N` de cômodos:

- No total pessoas núcleo familiar:

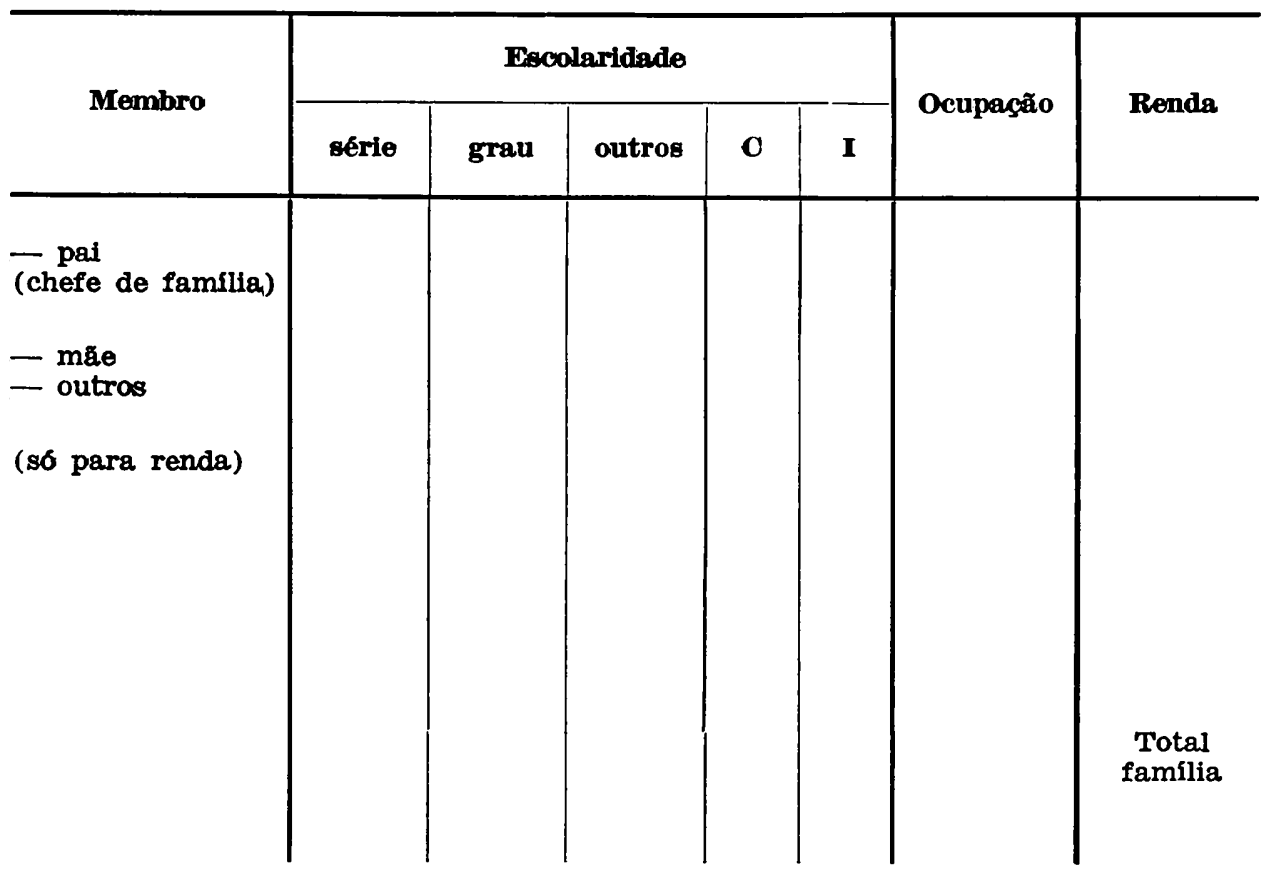


III. REGISTRO DAS RESPOSTAS DA MAE AS SEGUTNTES PERGUNTAS:

1. - A senhora está precisando de alguma coisa agora? $\operatorname{Sim}$ Não

- O quê?

- Porquê?

- Quem a senhora acha que pode ajudá-la nissa?

2. - A senhora gostaria de fazer alguma coisa aqui no hospital? Sim Não

- O quê?

- Porquê?

3. - A senhora espera alguma coisa das pessoas que trabalham aqui ? Sim Não

- O que?

- Porque

- Quem acha que poderia fazer isso?

4. - Como a senhora se sente aqui no hospital?

- Por que a senhora se sente assim? 